DOI: https://doi.org/10.46296/ig.v3i6.0014

\title{
ELABORACIÓN DE VINAGRE DE VINO A PARTIR DEL MUCÍLAGO Y EXUDADO DE CACAO CRIOLLO (THEOBROMA CACAO L.)
}

\section{ELABORATION OF WINE VINEGAR FROM MUCILAGE AND EXUDATION OF CREOLE COCOA (THEOBROMA CACAO L.)}

\author{
Vera-Loor José Edwin*; Cedeño-Palacios Nathalia Belén²; Mera-Vélez Sabina \\ Andrea $^{3}$ \\ ${ }^{1}$ Universidad Técnica de Manabí, UTM. Portoviejo, Ecuador. \\ ${ }^{2}$ Universidad Técnica de Manabí, UTM. Portoviejo, Ecuador. \\ 3Universidad Técnica de Manabí, UTM. Portoviejo, Ecuador.
}

*Correo: josveraloor@gmail.com

\begin{abstract}
Resumen
Grandes volúmenes de residuos son generados diariamente por la industria cacaotera debido al aprovechamiento exclusivo de la almendra, siendo este un problema de impacto ambiental que está relacionado con la contaminación de suelos y cuerpos de agua, producción de olores fétidos y deterioro del paisaje. Esto debido a que las pulpas y cáscaras del cacao son desechadas en terrenos aledaños a los cultivos cacaoteros. Es por esta razón, que la investigación tiene como finalidad discutir las bases teóricas que fundamentan la elaboración del vinagre de vino a partir del mucílago y exudado de cacao criollo (Theobroma Cacao L.), dada la necesidad de aprovechar el mucílago desechado en las cáscaras, que representan alrededor del $24 \%$ de los residuos totales, para así reducir el impacto ambiental y contribuir a la productividad nacional.
\end{abstract}

Palabras clave: industria cacaotera, cacao criollo, Theobroma Cacao L., mucílago, exudado.

\begin{abstract}
Large volumes of waste are generated daily by the cocoa industry due to the exclusive use of almonds, this being a problem of environmental impact, such as: contamination of soils and bodies of water, production of foul odors and deterioration of the landscape, due to the pulps and shells discarded on land adjacent to the cocoa plantations. It is for this reason that the purpose of the research is to discuss the theoretical bases that underpin the production of wine vinegar from mucilage and exudate of Creole cocoa (Theobroma Cacao L.), given the need to take advantage of the mucilage discarded in the shells, which represent around $24 \%$ of total waste, in order to reduce the environmental impact and contribute to national productivity.
\end{abstract}

Keywords: cocoa industry, Creole cocoa, Theobroma Cacao L., mucilage, exudate.

Información del manuscrito:

Fecha de recepción: 11 de mayo de 2020

Fecha de aceptación: 25 de junio de 2020

Fecha de publicación: 10 de julio de 2020 


\section{Introducción}

El cacao de tipo Theobroma cacao L., tiene gran importancia en la economía del Ecuador, por tratarse de un producto de exportación y materia prima para industrias locales de fabricación de chocolate y sus derivados (Alaniz et al., 2012).

Según López (2013) durante la fermentación, el mucílago o pulpa, se descompone en sustancias líquidas. El azúcar de la pulpa se transforma primero en alcohol, y seguidamente en ácido acético. Gran parte de la pulpa se libera en forma de exudado.

Rodríguez (2009) menciona que la concentración de alcohol en el exudado es, aproximadamente, del 2-3\% y la del ácido acético del 2,5\%. El contenido total de materia seca del exudado es de alrededor del $8 \%$, con un contenido de proteína bruta de un $20 \%$, aproximadamente.

A partir de lo expuesto se busca discutir la bibliografía relacionada con la obtención del vinagre a partir del aprovechamiento de los residuos resultantes de la fermentación espontánea del cacao, específicamente el exudado del mucílago que se genera en gran cantidad durante el proceso de extracción de la almendra fresca, y el mucílago desechado en las cáscaras.

\section{Mucílago y exudado de cacao}

El mucílago es una sustancia viscosa, generalmente hialina, que contiene el cacao. Además de ser un producto orgánico de origen vegetal, de peso molecular elevado, está conformado por polisacáridos celulósicos que contienen el mismo número de azúcares que las gomas y pectinas. Por otra parte, Torres et al. (2016) nos menciona que en un principio la pulpa es estéril, pero la presencia de azúcar y la adecuada acidez (pH 3,5), proporcionan excelentes condiciones para el desarrollo de microorganismos.

Tabla 1.

Constituyentes de la pulpa de cacao.

\begin{tabular}{|l|c|}
\hline Componentes & \% base húmeda \\
\hline Agua & $79,20-84,20$ \\
\hline Proteína cruda & $0,09-0,11$ \\
\hline Azúcares & $12,50-15,90$ \\
\hline Glucosa & $11,60-15,32$ \\
\hline Sacarosa & $0,11-0,90$ \\
\hline Pectinas & $0,90-1,19$ \\
\hline Ácido cítrico & $0,77-1,52$ \\
\hline Cenizas & $0,40-0,50$ \\
\hline
\end{tabular}

Fuente: Torres et al. (2016). 


\section{Vino}

Según Togores (2006) los vinos son elaborados a partir de un proceso común, con variaciones que dependen del tipo de vino. El vino es una bebida que se obtiene del jugo de uva, que es sometido a un proceso fermentación alcohólica mediante la presencia de levaduras. Sin embargo, el vino de frutas se define como una bebida que proviene de mostos de frutas frescas, sometidos a la fermentación alcohólica y que han sufrido procesos semejantes a los exigidos para los vinos (Ferreyra et al., 2009). El vino de frutas debe ser agradable al paladar y debe consumirse con moderación, además debe poseer un sabor similar a la fruta de la que está elaborado, mantener el aroma fresco y agradable que caracteriza a esta fruta (Arcos, 2014).

Aladren \& Crespo (1999) definieron como los parámetros más importantes que definen la calidad de un vino, la graduación alcohólica, la acidez, la fracción aromática y polifenólica, así como el color; siendo lógico que estos parámetros sean los que se utilicen en la valoración de la calidad del fruto.

\section{Fermentación alcohólica}

Graván (2008) señala que la fermentación alcohólica, también conocida como, fermentación etílica, es un proceso de tipo biológico en el cual se lleva a cabo una fermentación sin presencia de oxígeno. Este proceso se debe a las actividades de ciertos microorganismos, los cuales se encargan de procesar azúcares, como la glucosa, fructosa y otros carbohidratos, dando como resultado un alcohol a modo de etanol, $\mathrm{CO}_{2}$ (gas) y ATP (adenosín trifosfato), moléculas que son utilizadas por los propios microorganismos en sus metabolismos energéticos. La figura 1 muestra la ruta metabólica del proceso de fermentación de glucosa.

Vásquez (2007) menciona que la fermentación alcohólica es llevada a cabo principalmente por la levadura Saccharomyces cerevisiae, que es un hongo unicelular del grupo de los ascomicetos. En la naturaleza se encuentra sobre sustratos ricos en azúcares o en los exudados y savias dulces de algunas plantas. Por lo tanto, el conocimiento y percepción 
de la levadura está absolutamente condicionado por sus propiedades de fermentación del pan, el vino o la cerveza.

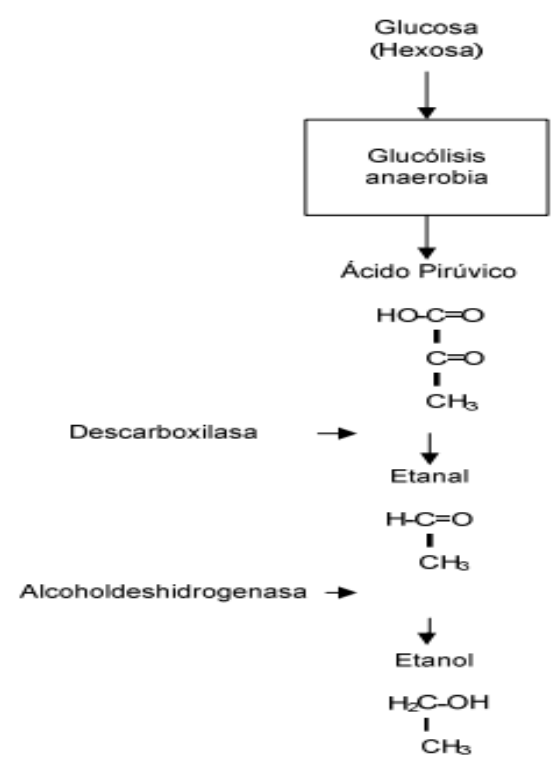

Figura 1.

Diagrama del proceso de fermentación de la glucosa

\subsection{Aspectos generales}

La fermentación alcohólica se puede definir como el proceso bioquímico por el cual las levaduras transforman los azúcares del mosto en etanol y $\mathrm{CO}_{2}$. Para que la fermentación tenga lugar, el mosto debe hallarse en condiciones de limitación de oxígeno (Graván, 2008). La fermentación alcohólica es conducida generalmente por las levaduras que pertenecen al género Saccharomyces y a la especie cerevisiae. Industrialmente, estas levaduras son organismos altamente especializados (Través, 2015). El sabor dulce y el contenido de alcohol de los vinos están interrelacionados porque la fermentación convierte los azúcares de la uva en etanol. A medida que se va produciendo alcohol, el contenido de azúcares disminuye y una vez que el vino no presenta sabor dulce teóricamente todo el azúcar ha sido fermentado y se dice que se ha producido vino seco. Los vinos secos contienen todo el alcohol que la uva en cuestión es capaz de proporcionar bajo las condiciones de fermentación, y que generalmente es de $12-14 \%$ de alcohol en volumen (Potter \& Hotchkiss, 1999). Desde el punto de vista organoléptico, el aroma del vino es el resultado de una compleja combinación de componentes que proporcionan a cada vino distintas características. Una gran fracción de componentes aromáticos son producidos durante la fermentación alcohólica (Mallouchos et al., 2003).

\subsubsection{Nutrientes y activadores}

Las levaduras fermentativas necesitan los azúcares para su catabolismo, es decir para obtener la energía necesaria para sus procesos vitales, además, requieren otros 
sustratos para su óptimo desarrollo.

El crecimiento de la levadura, bajo la limitación de ciertos nutrientes, como nitrógeno, carbono, azufre, potasio, fosforo $u$ otros elementos, sobre produce determinados metabolitos 0 enzimas (Muñoz \& Catrilaf, 2013).

Los zumos de la mayor parte de las frutas, son relativamente deficientes en compuestos nitrogenados, por lo que antes de iniciar la fermentación de este tipo de mostos, se le añaden nutrientes, como fosfato diamónico, cloruro amónico, sulfato amónico o carbonato amónico, en concentraciones de 0,1-0,3g/L.

\subsection{2. $\mathrm{pH}$ del sustrato}

Según Coronel (2008) el mosto de fermentación debe tener un determinado grado de acidez para que el proceso de fermentación transcurra normalmente. En el caso de la fermentación alcohólica inducida por Saccharomyces cerevisiae se puede mencionar que el pH óptimo de crecimiento para esta levadura, se encuentra en un rango de 4,5-5.

\subsubsection{Potencial Redox}

Es un concepto que establece las relaciones de óxido-reducción de las sustancias que interactúan en un proceso químico, permite definir la magnitud de la fuerza de óxidoreducción mediante la presión de hidrógeno $(\mathrm{rH})$, como medida general. La distribución completa de la zona en la que se encuentra la $\mathrm{rH}$ es la siguiente:

- Zona oxidante $\mathrm{rH}>25$.

- Zona intermedia rH: 15-25.

- Zona reductora $\mathrm{rH}<15$.

La presión de hidrógeno óptima para la multiplicación de la levadura de la especia Saccharomyces cerevisiae oscila alrededor de 11, con la fermentación se da inicio a los procesos de reducción, por lo que el rH disminuye (Paola et al., 2009). Las condiciones vitales para las levaduras son desfavorables a $\mathrm{rH}<9$.

\subsubsection{Temperatura de la solución nutritiva}

La temperatura desempeña un papel importante en las reacciones químicas y bioquímicas, su influencia es tan determinante que la regla de Van't Hoff señala que "a la temperatura ordinaria, un aumento de temperatura de diez grados duplica o triplica la velocidad de reacción". La temperatura óptima de crecimiento para Saccharomyces 
cerevisiae es $30^{\circ} \mathrm{C}$, manteniéndose la misma en soluciones nutritivas.

\subsubsection{Concentración inicial de azúcares}

Quimbita \& Rodríguez (2008) mencionan que la concentración de los azúcares fermentables presentes en el mosto, no debe ser muy elevada; ya que se produciría un estallido de la levadura, por la salida brusca del agua de su interior para equilibrar las concentraciones de solutos, lo que se denomina plasmosis. Generalmente se puede establecer que la mayoría de las levaduras toleran concentraciones de hasta $29^{\circ}$ Baumé $\left(50,75^{\circ}\right.$ Brix), aunque se conocen determinadas especies de levaduras como Saccharomyces Ludwigii y Schizosaccharomyces Pombe que toleran concentraciones mayores.

\section{Vinagre}

El vinagre (del latín «vinum acre», «vino agrio») es un líquido miscible en agua, con sabor agrio. Hoy en día la mayor parte del vinagre es obtenida en cultivo de tanque sumergido, descrito por primera vez en 1949 por Otto Hromatka y Heinrich Ebner. En este método, el alcohol se fermenta a vinagre en un tanque agitado continuamente, y se suministra oxígeno burbujeando aire a través de la solución. Usando aplicaciones modernas de este método, se puede preparar vinagre al $15 \%$ de ácido acético en sólo 24 horas en un proceso por lotes, incluso de $20 \%$ en 60 horas (González, 2014).

\section{Fermentación acética}

La descripción del género Acetobacter según Rodríguez \& Sarabia (2012) refleja que estas células presentan una estructura que va desde la forma elipsoidal a la alargada, recta o ligeramente curvada, encontrándose también algunas especies de tipo esféricas, alargadas, hinchadas, curvadas y filamentosas. Pueden ser móviles o no móviles, si son móviles son peritricas o laterales, no forman endosporas, son Gram negativas y en algunos casos Gram variables, son aerobias estrictas, por lo que tienen un metabolismo respiratorio en que el oxígeno es el aceptor final de electrones, forman también colonias pálidas, son catalasa positiva y oxidasa negativa, no licúan la gelatina y no forman indol $\circ \mathrm{H}_{2} \mathrm{~S}$, oxidan el etanol a ácido acético y el acetato y el lactato a $\mathrm{CO}_{2}$ y $\mathrm{H}_{2} \mathrm{O}$, el 
$\mathrm{pH}$ óptimo para su crecimiento es 5,4-6,3, el género Acetobacter se encuentra en flores, frutas, vino de uva, sidra cerveza, vinagre, virutas de madera generadores de vinagre y acetificadores, entre otros (Moeller \& Tomasini, 2004).

\subsection{Aspectos generales de la fermentación acética}

Los principales factores que intervienen en la fermentación acética son el tipo y la densidad de bacterias presentes, la temperatura, la concentración de etanol, de ácido acético y de oxígeno disuelto. La incorporación de aire es un proceso esencial, dado el carácter aerobio de las bacterias acéticas (Llaguno \& Polo, 1991).

Por otra parte, las condiciones del inóculo son un parámetro importante para desarrollar una óptima fermentación. El cultivo selectivo de bacterias acéticas debe estar en fase exponencial de crecimiento, con una concentración de biomasa total, del orden de 500 x $106 \mathrm{UFC} / \mathrm{mL}$, de acuerdo a De Ory et al., 2002.

La temperatura de operación óptima que se utiliza para la fermentación acética, se encuentra entre el rango de $30-31^{\circ} \mathrm{C}$, la cual puede ser alcanzada, en la mayoría de los casos por un intercambiador de calor interno, conectado a un termostato (De Ory et al., 2004a). Por su parte, temperaturas menores a $26^{\circ} \mathrm{C}$ provocan que la fermentación se desarrolle a baja velocidad, no obstante, elevadas temperaturas, esto es por encima de los $34^{\circ} \mathrm{C}$, aceleran la evaporación del alcohol, ácido acético y sustancias volátiles que contribuyen a las características del sabor y aroma del vinagre. (Weiser, 1962). La calidad final del vinagre está determinada por el sistema de acetificación empleado, materia prima, sustrato y eventualmente por el período de envejecimiento o maduración en barriles de madera (Tesfaye et al., 2002).

Las características importantes para seleccionar las especies de Acetobacter aptas para la producción de ácido acético son:

- Se detecta claramente la acción inhibidora por parte del sustrato (etanol) a concentraciones superiores a $50 \mathrm{~g} / \mathrm{L}$, registrándose muy escaso crecimiento por encima de $150 \mathrm{~g} / \mathrm{L}$.

- A pesar de ser un proceso aerobio, se observa también 
acción inhibidora por parte del oxígeno desde concentraciones del orden de 5ppm (oxígeno disuelto), bastante inferiores a la saturación.

- Por último, se presenta acción inhibidora por parte del producto (ácido acético) a concentraciones superiores a 20g/L; aunque el ácido acético presenta una ligera acción potenciadora a concentraciones más bajas. De esta forma, cuando se opera en medios con cierta concentración inicial del ácido, se obtienen velocidades de proceso superiores a las obtenidas en ausencia total del mismo.

- En cuanto al $\mathrm{pH}$, puede afirmarse que las bacterias acéticas presentan un crecimiento óptimo en el rango de $\mathrm{pH}$ de 5 a 6,5; aunque se observa gran capacidad para sobrevivir a $\mathrm{pH}$ entre 3 y 4 . (Chile Patente $\mathrm{n}^{\circ}$ ISSN 0716-8756, 1994).

\subsection{Influencia de la temperatura}

La temperatura del medio influye sobre el crecimiento del microorganismo, por lo cual se propone una temperatura óptima de fermentación acética comprendida dentro del rango $28-32^{\circ} \mathrm{C}$, sin embargo, cuando la temperatura es superior a $33^{\circ} \mathrm{C}$, ocurre un proceso de desactivación bacteriana, además de aumentar las pérdidas de alcohol y productos volátiles, las enzimas son desnaturalizadas, la membrana dañada, causando que los constituyentes se dispersen y el organismo sea más sensible a los efectos tóxicos de la célula $y$, al disminuir por debajo de $25{ }^{\circ} \mathrm{C}$, también se inhibe gradualmente el desarrollo bacteriano en el proceso. (Llaguno \& Polo, 1991).

\subsection{Influencia de la agitación}

Según Villagomez (2013) la velocidad de agitación en la fermentación influye directamente sobre el desarrollo del microorganismo, debido a que una adecuada agitación permite potenciar la captación de oxígeno en el microorganismo, la condición óptima de agitación en el proceso, según estudios previos es de 400 rpm.

\subsection{Influencia de la aireación}

La incorporación de aire es un proceso esencial, dado el carácter aerobio de las bacterias acéticas.

Además de la cantidad de aire suministrado, se debe considerar la 
pureza y calidad de éste, las bacterias acéticas son sensibles a contaminantes presentes en el aire. (Llaguno \& Polo 1991). En este tipo de fermentaciones, la concentración de oxígeno disuelto es uno de los factores determinantes de la velocidad global del proceso, sin embargo, cuando se aborda el modelado cinético de la fermentación acética, se suele evitar la presencia de parámetros relacionados con el oxígeno, de forma que no se han propuesto modelos que incluyan dicha variable con carácter cuantitativo en las ecuaciones cinéticas (Gómez et al., 1994). La medida para cuantificar este parámetro se expresa en vvm (volumen de aire por volumen en el medio por minuto), las condiciones óptimas de operación en cuanto a la aireación en el proceso son de 0,5 vvm, dicha condición proporciona los máximos valores del coeficiente de transferencia de oxígeno al medio líquido (Villagomez, 2013).

\subsection{Nutrientes}

La producción del ácido acético tiene lugar por un proceso estrictamente aerobio en el que se suministra alcohol etílico (etanol) a bacterias del ácido acético fijadas sobre soportes diversos. Las bacterias van oxidando el alcohol y se recoge finalmente el ácido (Rivera, 2011). Las exigencias nutritivas de las bacterias acéticas son escasas, encontrándose en sus necesidades más restrictivas los compuestos nitrogenados, los fosfatos y algunas vitaminas del complejo B (Chile Patente nํ ISSN 0716-8756, 1994).

\section{Conclusiones}

La factibilidad económica que se debe disponer en primera instancia para la posible puesta en marcha de los procesos fermentativos que permitan aprovechar los productos agrícolas, subproductos y residuos en el Ecuador y paliar de esta forma la consecuente contaminación.

Se identifica la fermentación natural que existe en el exudado, debido a la intervención de la levadura, así como los requerimientos físicos y condiciones extremas o limitantes que inhiben su crecimiento; con dicha información se determinó la influencia de cada variable.

\section{Bibliografía}

Aladren, F. \& Crespo, I. (1999). Estudio de la relación entre el color de la uva tinta y el color del vino. Viticultura / Enología profesional. 63, 23-34. 
Alaniz, E., Arvisú, S., González, K. (2012). Producción de postres y vinagre a partir del exudado de cacao. Venezuela: Tesis. Disponible en: http://avdiaz.files.wordpress.c om/2012/08/protocolocacao.pdf

Arcos-Parreño, J. (2014). Evaluación de las características del vino seco de arazá (Eugenia stipitata) con dos tipos de levaduras $y$ tres concentraciones de sacarosa en la planta de frutas $y$ hortalizas de la Universidad Estatal de Bolívar (Bachelor's thesis, Universidad Estatal de Bolívar. Facultad de Ciencias Agropecuarias. Escuela de Ingeniería Agroindustrial).

Coronel, M. (2008). Los vinos de frutas. Facultad de Ciencias de la Ingeniería, Universidad Tecnológica Equinoccial. Quito, Ecuador.

De Ory, I., Romero, L., Cantero, D. (2002). Optimum starting-up protocol of a pilot plant scale acetifier for vinegar production. Journal of Food Engineering. 52, 31-37.

De Ory, I., Romero, L., Cantero, D. (2004a). Operation in semicontinuous with a closed pilot plant scale acetifier for Vinegar production. Journal of Food Engineering. 63, 39-45.

De Ory, I., Romero, L., Cantero, D. 2004b. Optimization of immobilization conditions for vinegar production. Siran, wood chips and polyurethane foams as carries for Acetobacter aceti. Process Biochemistry. 39, 547-555.

Ferreyra, M. M., Schvab, M. D. C., Gerard, L. M., Zapata, L. M., Davies, C. V., \& Hours, R. A. (2009). Fermentación alcohólica de jugo de naranja con S. cerevisiae. Ciencia, docencia y tecnología, 20(39), 143-158.

Gómez, J. M., Romero, L. E., Caro, L., \& Cantero, D. (1994). Application of a gas recirculation system to industrial acetic fermentation processes. Biotechnology techniques, 8(10), 711-716.

González-Alba, A. (2014). Diseño de una planta de producción de vinagre a partir de melazas de remolacha azucarera.

Universidad de Cádiz.

Graván-Pérez, C. (2008). Diseño de una instalación destinada a los procesos de fermentación alcohólica y maloláctica.

Llaguno, C. \& Polo, M. C. (1991). E vinagre de vino. Consejo Superior de Investigaciones Científicas. Madrid. España. $238 \mathrm{p}$.

López-Limones, J. A. (2013). Obtención de una bebida alcohólica a partir de la fermentación de mucílago de cacao (Theobroma cacao L.) en la planta de frutas $y$ hortalizas de la Universidad 
Estatal de Bolívar (Bachelor's thesis, Universidad Estatal de Bolívar. Facultad de Ciencias Agropecuarias. Escuela de Ingeniería Agroindustrial).

Mallouchos, A., Komaitis, M., Koutinas, A., Kanellaki, M. (2003). Wine fermentations by immobilized and free cells at different temperatures. Effect of immobilization and temperature on volatile byproducts. Food Chemistry. 80, 109-113.

Moeller, G., \& Tomasini, A. (2004). Microbiología de lodos activados. Memorias de curso internacional de sistemas integrados de tratamiento de aguas residuales y su reúso para un medio ambiente sustentable [Internet]. Bogotá: Instituto Mexicano de Tecnología del Agua (IMTA).

Muñoz, M., \& Catrilaf, G. (2013). Estimación de parámetros cinéticos de Saccharomyces cerevisiae en sistema de fermentación batch bajo distintas condiciones de crecimiento.

Paola, M. Y., Nally, M. C., Eugenia, T. M., \& De, C. (2009). Estudio cualitativo de actividades enzimáticas y fenómeno killer en levaduras vínicas. Revista Enología, 1(6), 1-11.

Potter, N. \& Hotchkiss, J. (1999). Ciencia de los alimentos. Zaragoza, España: Editorial Acribia. 667p.
Quimbita-Caiza, F. A., \& Rodríguez Manrique, P. A. (2016). Aprovechamiento del exudado y la placenta del cacao (Theobroma cacao L.) para la producción de una bebida alcohólica de baja concentración y elaboración de néctar (Bachelor's thesis, Quito, 2008).

Rivera, A. S. (2011). Obtención de vinagre a partir de la biofermentación de residuos de banano y otras frutas para su industrialización (Bachelor's thesis, Quito: Universidad de las Américas, 2011).

Rodríguez, C. M., \& Sarabia, C. I. (2012). Efecto del método de fermentación acética en las características físicoquímicas y sensoriales en vinagre de naranja agria (Citrus $x$ aurantium) y piña (Ananas comosus) (Bachelor's thesis, Zamorano: Escuela Agrícola Panamericana, 2012).

Rodríguez-Manrique, J. L. (2009). Aprovechamiento del exudado de cacao en la gastronomía (Doctoral dissertation).

Tecnológica, C. (1994). Chile Patente no ISSN 0716-8756.

Tesfaye, W., Morales, M., GarciaParrilla, A., Troncoso, A. (2002). Wine Vinegar: technology, authenticity and quality evaluation. Trends in 
Food Science and

Technology, 13, 12-21.

Togores, J. H. (2006). La calidad del vino desde el viñedo. MundiPrensa Libros.

Torres, C. A. V., Ocampo, R. D., Rodríguez, W. M., Velasco, R. S., Chang, J. F. V., \& Cedeño, C. B. (2016). Utilización del mucílago de cacao, tipo nacional y trinitario, en la obtención de jalea. Revista ESPAMCIENCIA, 7(1), 51-58.

Través, L. P. (2015). Obtención, Estabilización y Selección de Levaduras Híbridas de Saccharomyces de Interés Enológico (Doctoral dissertation, Universidad de Valencia).
Villagomez-Garcia, S. (2013). Optimización $y$ aprovechamiento del residuo (exudado del mucílago de la almendra fresca del caco (Theobroma cacao L.) CCN51 en la elaboración de vinagre (Bachelor's thesis, Universidad Tecnológica Equinoccial. Facultad: Ciencias de la Ingeniería).

Weiser, H. (1962). Practical food microbiology. The Avi Publishing Company, Inc. USA. 354p. 